\title{
Assessment of disease progression in dysferlinopathy
}

\section{A 1-year cohort study}

\author{
Correspondence \\ Prof. Straub \\ volker.straub@ \\ newcastle.ac.uk
}

jia Feng, MSc, Avital Cnaan, PhD, Michelle Eagle, PT, PhD, Karen Bettinson, MSc, Laura E. Rufibach, PhD, Robert Muni Lofra, PT, Andrew M. Blamire, PhD, Pierre G. Carlier, MD, PhD, Plavi Mittal, PhD, Linda Pax Lowes, PT, PhD, Lindsay Alfano, DPT, Kristy Rose, PT, PhD, Tina Duong, MPT, Katherine M. Berry, PT, Elena Montiel-Morillo, PT, Irene Pedrosa-Hernández, PT, Scott Holsten, PT, Mohammed Sanjak, PT, PhD, Ai Ashida, DPT, Chikako Sakamoto, PT, Takayuki Tateishi, PT, Hiroyuki Yajima, PT, Aurélie Canal, PT, Gwenn Ollivier, PT, Valerie Decostre, PhD, Juan Bosco Mendez, MD, Nieves Sánchez-Aguilera Praxedes, PT, Simone Thiele, PT, Catherine Siener, PT, MHS, Jeanine Shierbecker, PT, Julaine M. Florence, PT, MHS, DPT, Bruno Vandevelde, Brittney DeWolf, PT, DPT, PCS, Meghan Hutchence, BSc, PT, Richard Gee, MPT, Juliana Prügel, PT, Elke Maron, PT, Heather Hilsden, BA, Hanns Lochmüller, MD, Ulrike Grieben, MD, Simone Spuler, MD, Carolina Tesi Rocha, MD, John W. Day, MD, Kristi J. Jones, MD, PhD, Diana X. Bharucha-Goebel, MD, Emmanuelle Salort-Campana, MD, Matthew Harms, MD, Alan Pestronk, MD, Sabine Krause, MD, PhD, Olivia Schreiber-Katz, MD, Maggie C. Walter, MD, MA, Carmen Paradas, MD, PhD, Jean-Yves Hogrel, PhD, Tanya Stojkovic, MD, Shin'ichi Takeda, MD, PhD, Madoka Mori-Yoshimura, MD, PhD, Elena Bravver, MD, Susan Sparks, MD, Jordi Díaz-Manera, MD, PhD, Luca Bello, MD, PhD, Claudio Semplicini, MD, PhD, Elena Pegoraro, MD, PhD, Jerry R. Mendell, MD, Kate Bushby, MD, and Volker Straub, MD, for the Jain COS Consortium

Neurology ${ }^{\circledR}$ 2019;92:e461-e474. doi:10.1212/WNL.0000000000006858

\section{Abstract}

\section{Objective}

To assess the ability of functional measures to detect disease progression in dysferlinopathy over 6 months and 1 year.

\section{Methods}

One hundred ninety-three patients with dysferlinopathy were recruited to the Jain Foundation's International Clinical Outcome Study for Dysferlinopathy. Baseline, 6-month, and 1-year assessments included adapted North Star Ambulatory Assessment (a-NSAA), Motor Function Measure (MFM-20), timed function tests, 6-minute walk test (6MWT), Brooke scale, Jebsen test, manual muscle testing, and hand-held dynamometry. Patients also completed the ACTIVLIM questionnaire. Change in each measure over 6 months and 1 year was calculated and compared between disease severity (ambulant [mild, moderate, or severe based on a-NSAA score] or nonambulant [unable to complete a 10-meter walk]) and clinical diagnosis.

\section{Results}

The functional a-NSAA test was the most sensitive to deterioration for ambulant patients overall. The a-NSAA score was the most sensitive test in the mild and moderate groups, while the $6 \mathrm{MWT}$ was most sensitive in the severe group. The 10-meter walk test was the only test showing significant change across all ambulant severity groups. In nonambulant patients, the MFM domain 3, wrist flexion strength, and pinch grip were most sensitive. Progression rates did not differ by clinical diagnosis. Power calculations determined that 46 moderately affected patients are required to determine clinical effectiveness for a hypothetical 1-year clinical trial based on the a-NSAA as a clinical endpoint.

\section{Conclusion}

Certain functional outcome measures can detect changes over 6 months and 1 year in dysferlinopathy and potentially be useful in monitoring progression in clinical trials.

\section{ClinicalTrials.gov identifier: NCT01676077.}




\section{Glossary}

a-NSAA = adapted North Star Ambulatory Assessment; COS = Jain Clinical Outcome Study in Dysferlinopathy; HHD = handheld dynamometry; LGMD2B = limb girdle muscular dystrophy 2B; $\mathbf{M F M}=$ Motor Function Measure; $\mathbf{M M T}=$ manual muscle testing; $6 \mathrm{MWT}=6$-minute walk test; SRM = standardized response mean.

Dysferlinopathy is a rare, recessively inherited muscular dystrophy caused by mutations in the DYSF ${ }^{1-4}$ gene. Potential therapies are in development, and some of them have entered human clinical trials (NCT02579239, NCT01863004, NCT02710500). As the development of newly licensed and emerging treatments for Duchenne muscular dystrophy ${ }^{5,6}$ and spinal muscular atrophy type $1^{7}$ has shown, proving efficacy and satisfying regulators can be difficult in slowly progressive and varied conditions. ${ }^{8}$

Appropriate powering of a clinical trial requires understanding of disease progression and responsiveness of various outcome measures over time. ${ }^{9}$ Selection of outcome measures for clinical trials in dysferlinopathy is particularly challenging. Dysferlinopathy is characterized by a range of ages at onset and patterns of weakness and severity, ${ }^{4,10}$ variable rate of progression, ${ }^{4}$ modifying factors that are not clearly elucidated, ${ }^{10-13}$ and no appropriate measures for monitoring progression. While some measures such as the Motor Function Measure (MFM) have been shown to be reliable in dysferlinopathy, ${ }^{14}$ the variability of progression makes it difficult to demonstrate responsiveness in small cohorts.

The Jain Clinical Outcome Study in Dysferlinopathy (COS) aims to address these difficulties by characterizing the clinical, biochemical, and radiologic parameters of 209 patients with dysferlinopathy over 3 years.

This article summarizes findings from a planned interim analysis of baseline, 6-month, and year 1 data to determine whether disease progression is detectable and which measures are most able to detect this progress. We propose a power calculation using the most sensitive measures to determine a potential clinical trial cohort required to demonstrate significant functional change.

\section{Methods}

\section{The cos study}

The COS study is an international collaborative study of patients with a genetic and/or protein assay-confirmed diagnosis of dysferlinopathy. ${ }^{4}$ Screening, baseline, 6-month, and 1-year visits took place between October 2012 and March 2016. One hundred ninety-seven of the original 209 recruited patients completed a baseline visit. Of the original 209 patients, 7 did not meet inclusion criteria, and 5 chose not to continue past the screening visit (figure 1). Full inclusion and exclusion criteria, the study protocol, and patient demographics have been described previously. ${ }^{4}$

\section{Standard protocol approvals, registrations, and patient consents}

The study was initially approved by the following: NRES Committee North East-Newcastle \& North Tyneside on February 2, 2012 (reference 211/NE/0360/R\&D 5918). The study was also approved by ethics review boards in each country. All patients provided written informed consent. The trial was registered at ClinicalTrials.gov (NCT01676077).

\section{Functional outcome measures}

Clinical assessments were standardized through trainings at investigator meetings, and all evaluations were performed by trained clinicians. Assessments included the adapted North Star Ambulatory Assessment (a-NSAA), ${ }^{4}$ MFM-20, timed function tests (timed rise from floor, 10-m walk/run, 4-stair climb and descend, Timed Up and Go, and the 6-minute walk test $[6 \mathrm{MWT}])$, Brooke Upper Extremity Scale, Jebsen Hand Function Test, manual muscle testing (MMT), and hand-held dynamometry (HHD). No assessments have been specifically validated in a dysferlin-specific population. These assessments were chosen because of their widespread suitability for limb girdle muscular dystrophy. The MFM-20 was selected over the MFM-32 to reduce patient fatigue and duplication. All assessments were attempted for ambulant patients. Nonambulant patients did not complete the a-NSAA or ambulation-based timed function tests.

Muscle strength was assessed with an 11-point scale for MMT. ${ }^{4}$ The best of 3 attempts for HHD was used for analysis.

Functional ability was assessed with qualitative scales and timed tests. Total scores were calculated for the a-NSAA ${ }^{15}$ in ambulant patients, and the MFM-20 and the Brooke scale were calculated in all patients. The MFM-20 was also analyzed on the basis of its 3 components: D1 (standing and transfers), D2 (axial and proximal), and D3 (distal). Any patient with an incomplete score was excluded from analysis for that test. To account for patients who became nonambulant or unable to complete timed function tests due to disease progression, timed test values were converted to velocity measures (either meter per second or task per second), with a $0-\mathrm{m} / \mathrm{s}$ velocity assigned for the first instance a patient was unable to complete the test.

\section{Patient perception of progression}

The ACTIVLIM questionnaire, a Rasch-built patientreported outcome measure, ${ }^{16}$ was used to capture patientreported functional ability. The total score, out of a maximum of 36, was compared between visits. A higher score indicates greater functional ability. 


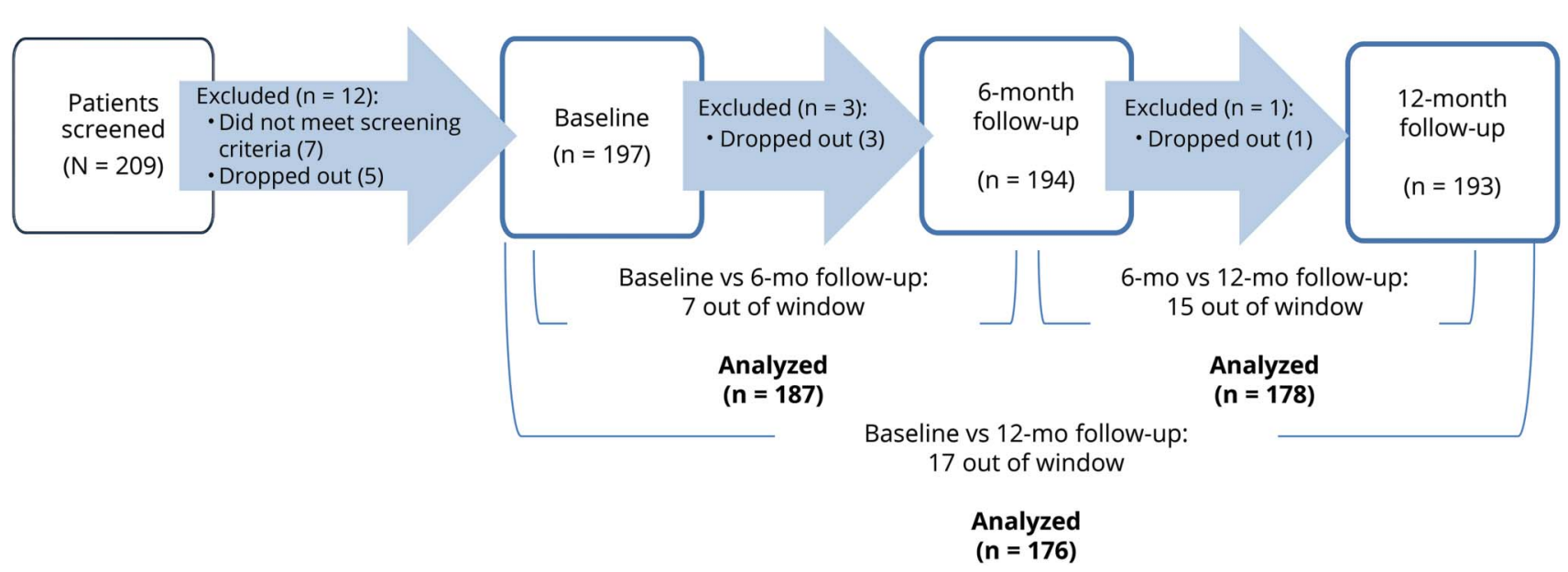

Number of patients who completed each assessment (baseline, 6 months, and 12 months) and how many of them were used for each analysis window.

\section{Statistical analysis}

Statistical analysis was completed with SAS 9.3 (SAS Institute Inc, Cary, NC). Mean and median change scores were calculated for each test between baseline and 6 months, 6 months and year 1 , and baseline and year 1 . Data from some visits were excluded if the visit occurred \pm 2 months outside the scheduled appointment date. A majority of functional outcome measures were not normally distributed; thus, comparisons between baseline and follow-up time points were conducted with the Wilcoxon signed rank-sum test and standardized response mean (SRM). ${ }^{17}$ A comparison was made between the performance of patients with the most common clinical diagnoses of limb girdle muscular dystrophy 2B (LGMD2B) and Miyoshi myopathy with Kruskal-Wallis test with Steel-Dwass-Critchlow-Fligner correction for multiple comparisons. ${ }^{18}$

Nonambulant patients (unable to walk 10 meters with usual orthotics and walking aids) were compared to 3 categories of ambulant patients: ambulation affected severely, moderately, or mildly. Using patients' a-NSAA scores at baseline, we defined ambulant severity categories based on a clinical impression of disease severity and binomial distribution of a-NSAA scores, with cut points of 0 to 10 (severe disease severity), 11 to 40 (moderate disease severity), and $41+$ (mild disease severity). The lower cut point was based on the end of the first a-NSAA peak, and the high cut point was placed at the start of the second peak, with the wide spread in between representing a plateau between peaks. Significance was defined as $p \leq 0.05$. Results are expressed as median change (range) and $p$ value.

Power analyses to support a hypothetical future clinical trial were conducted to estimate the sample size required to detect significant statistical differences in progression over the course of 1 year with PASS 14 software. Because change scores were normally distributed, calculations used mean change scores and SDs of the functional measure that demonstrated most change over time. For this analysis, the a-NSAA was used, which limited estimates to ambulant patients only. Sample sizes needed to evaluate a variety of expected drug effects were calculated for reference, including halting of disease progression (i.e., assuming mean progression estimates from the current sample among untreated and no progression among treated patients), reflective of potential protein-restoring genetic therapies. An a level of $0.05,80 \%$ power, and a treatedto-untreated ratio of 1:1 were assumed. For comparison with a widely used measure in muscular dystrophy, sample sizes were also calculated on the basis of the 6MWT.

\section{Data availability statement}

Deidentified cohort level data can be requested. All protocol assessments are in the public domain apart from the a-NSAA, which can be requested from the steering group (publication in draft). The statistical plan is detailed above. All data for this natural history study will be stored for at least 5 years after the end of the study. Data can be requested by all interested stakeholders for clinical research and trial planning. Data requests are reviewed by the Jain COS Steering Committee, who can be contacted via the corresponding author.

\section{Results}

Of the initial 197 eligible enrolled patients, 3 patients withdrew after baseline, and 1 withdrew after 6 months. This is summarized in figure 1. Patients included in this analysis were between 11 and 86 years of age at baseline and were at all stages of disease progression, from asymptomatic hyperCKemia to nonambulant.

\section{Functional outcome measures}

Functional outcome measure results are summarized in tables 1 and 2, figure 2, and table e-1 (available from Dryad, doi.org/ $10.5061 /$ dryad.tp08m60). Some of the assessments, by their 
Table 1 Change in scores of functional tests from baseline to 6 months, 6 months to 1 year, and baseline to 1 year for the a-NSAA, MFM, Jebsen, Brooke, patient-reported ACTIVLIM, and 6-minute walk tests

\begin{tabular}{|c|c|c|c|c|c|c|c|c|c|c|c|}
\hline \multirow[b]{2}{*}{ Outcome measure } & \multirow{2}{*}{$\begin{array}{l}\text { Baseline } \\
\text { median } \\
\text { score }\end{array}$} & \multicolumn{3}{|c|}{ Change in score, baseline- 6 mo } & \multicolumn{3}{|c|}{ Change in score, 6 mo-1 y } & \multicolumn{3}{|c|}{ Change in score, baseline-1 y } & \multirow[b]{2}{*}{ SRM } \\
\hline & & $\mathbf{n}$ & Median (range) & $p$ Value & $\mathbf{n}$ & Median (range) & $p$ Value & $\mathbf{n}$ & $\begin{array}{l}\text { Median } \\
\text { (range) }\end{array}$ & $p$ Value & \\
\hline Total North Star score ${ }^{a}$ & 19 & 130 & $-1.00(-19.0$ to 19.0$)$ & $<0.0001^{a}$ & 119 & $0.00(-14.0$ to 5.00$)$ & $0.025^{a}$ & 117 & $-2.00(-16.0$ to 7.00$)$ & $<0.0001^{b}$ & 0.61 \\
\hline Total MFM score ${ }^{a}$ & 45 & 161 & $-1.00(-17.0$ to 7.00$)$ & $<0.0001^{\mathrm{a}}$ & 148 & $-0.50(-11.0$ to 11.0$)$ & $0.0226^{a}$ & 149 & $-1.00(-13.0$ to 6.00$)$ & $<0.0001^{b}$ & 0.44 \\
\hline MFM D1 score ${ }^{a}$ & 10 & 166 & $0.00(-7.00$ to 4.00$)$ & $0.0007^{\mathrm{a}}$ & 152 & 0.00 (-7.00 to 6.00$)$ & $0.0033^{\mathrm{a}}$ & 151 & $-1.00(-8.00$ to 6.00$)$ & $<0.0001^{\mathrm{b}}$ & 0.4 \\
\hline MFM D2 score ${ }^{c}$ & 23 & 166 & $0.00(-12.0$ to 5.00$)$ & $0.0004^{c}$ & 154 & $0.00(-6.00$ to 10.0$)$ & 0.7945 & 157 & $0.00(-8.00$ to 5.00$)$ & $0.0171^{b}$ & 0.19 \\
\hline MFM D3 score ${ }^{b}$ & 11 & 174 & $0.00(-3.00$ to 2.00$)$ & 0.0655 & 158 & 0.00 (-3.00 to 3.00$)$ & 0.1431 & 160 & 0.00 (-6.00 to 2.00$)$ & $0.0011^{b}$ & 0.26 \\
\hline Brooke Upper Extremity Scale ${ }^{b}$ & 1 & 181 & $0.00(-2.00$ to 5.00$)$ & 0.2025 & 164 & $0.00(-5.00$ to 2.00$)$ & 0.477 & 164 & $0.00(-2.00$ to 2.00$)$ & $0.0334^{\mathrm{b}}$ & 0.18 \\
\hline ACTIVLIM total score ${ }^{a}$ & 26 & 180 & $0.00(-9.00$ to 8.00$)$ & $0.0042^{\mathrm{a}}$ & 165 & $0.00(-9.00$ to 10.0$)$ & $0.0026^{\mathrm{a}}$ & 164 & $-1.00(-8.00$ to 6.00$)$ & $<0.0001^{b}$ & 0.46 \\
\hline Jebsen writing time taken, s & 12.7 & 180 & $0.10(-17.3$ to 14.9$)$ & 0.5794 & 165 & $0.10(-11.3$ to 30.5$)$ & 0.56 & 162 & $-0.15(-14.4$ to 28.1$)$ & 0.7109 & 0.11 \\
\hline 6-min walk distance, meters $/ \mathrm{min}^{\mathrm{c}}$ & 331 & 124 & $-4.00(-95.0$ to 123$)$ & 0.2041 & 112 & $-7.00(-110$ to 51.0$)$ & $0.0003^{c}$ & 113 & $-13.0(-123$ to 142$)$ & $<0.0001^{b}$ & 0.37 \\
\hline
\end{tabular}

Abbreviations: a-NSAA = adapted North Star Ambulatory Assessment; MFM = Motor Function Measure; SLM = standardized response mean.

$p$ Values were calculated with the Wilcoxon signed-rank method. The SRM is a measure of effect size reported for change over 1 year.

a Consistent significant change over 6 months.

b Change over 1 year.

${ }^{c}$ Change over one 6-month period but not both 6-month periods. 


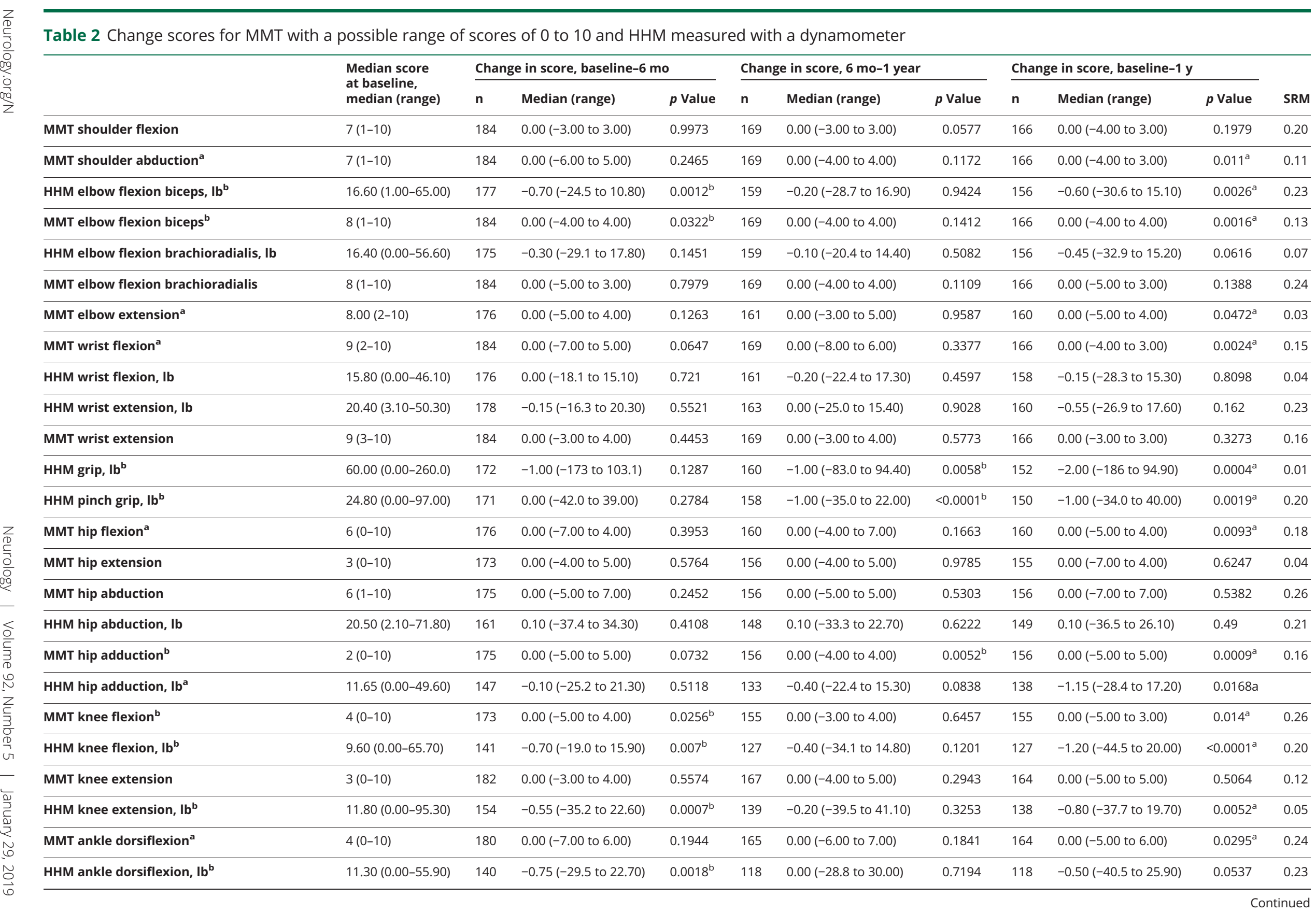


nature, are suitable only for ambulant patients. In addition, some patients did not complete all assessments because of equipment or individual patient factors such as recent injury and were excluded from analysis of that assessment. The number of patients who completed each assessment is listed.

The a-NSAA, MFM-20 (total and subdomain D1), the Timed $\mathrm{Up}$ and Go, and timed 10-meter walk showed significant change in median score over both 6-month periods and 1 year (table 1 and figure 2); no MMT or HHD values changed consistently over both 6-month windows (table 2).

The MFM D2, some MMT and HHD, velocity to rise from floor, climb 4 stairs, descend 4 stairs, and the 6MWT showed significant change over only one 6-month window and over 1 year (tables 1 and 2 and figure 2).

The MFM D3, some MMT and HHD, and the Brooke scale showed change in median score at 1 year but did not change over either 6-month windows (tables 1 and 2).

The timed test demonstrating the greatest change in velocity was the 10 -meter walk, changing $-0.1 \mathrm{~m} / \mathrm{s}$ (range -1.24 to $0.55 \mathrm{~m} / \mathrm{s}$ ) from a baseline median velocity of $1.11 \mathrm{~m} / \mathrm{s}$ (range $0.00-4.55 \mathrm{~m} / \mathrm{s}$ ). The velocity of all timed tests at year 1 slowed by almost $10 \%$ of baseline velocity for that task (figure 2).

The Jebsen Hand Function Test and remaining MMT and HHD tests showed no change over 1 year.

The tests most responsive to change for the whole cohort, as calculated by the SRM, were NSAA (SRM 0.61), 10-meter walk/run velocity (0.56), ACTIVLIM (0.46), rise from floor velocity (0.44), and MFM total score (0.44).

When assessed by severity subgroup, for ambulant patients, the a-NSAA was the most sensitive test in the mildly (SRM 0.44 ) and moderately (SRM 0.89) affected groups, while the 6MWT was most sensitive in the severely affected ambulant group (SRM 0.9). The 10-meter walk was the only test showing significant change in all ambulant subgroups. For nonambulant patients, the most sensitive test was the MMT for wrist flexion (SRM 0.69), while the most sensitive combined measure was the distal domain of the MFM (SRM 0.46). Table e-1 (available from Dryad doi.org/10.5061/ dryad.tp08m60) shows SRM values for all assessments by severity subgroup. Change in functional test scores (MFM and a-NSAA) did not differ between the 2 most common clinical diagnoses of LGMD2B and Miyoshi myopathy (table 3).

\section{Patient perception of progression}

Responses recorded by the ACTIVLIM questionnaire supported the deterioration in function, with the ACTIVLIM score decreasing statistically significantly over both 6 and 12 months (table 1). 
A. Time to descend 4 stairs

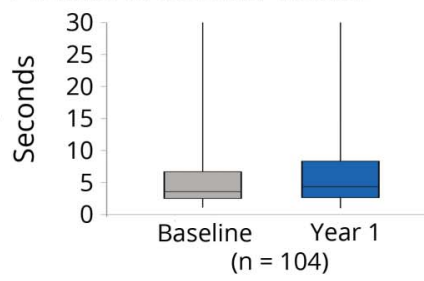

B. Time to walk 10 meters

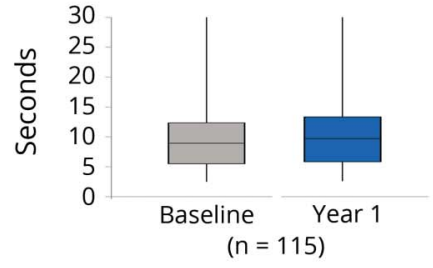

C. Time taken to rise from floor

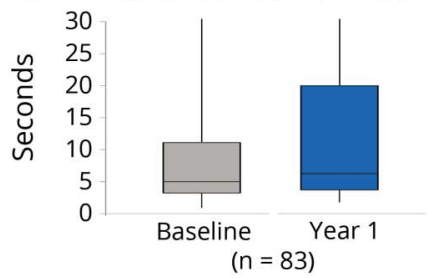

D. Time to climb 4 stairs

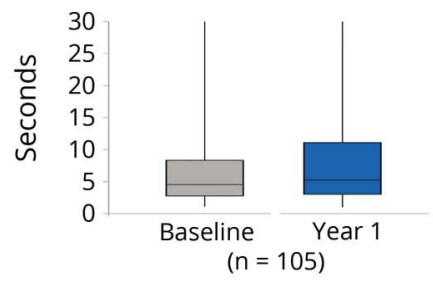

E. Timed up-and-go

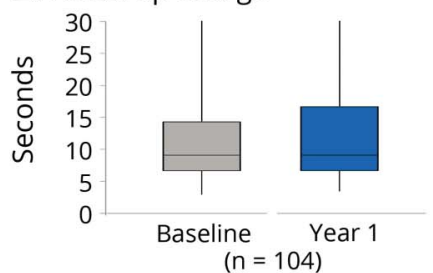

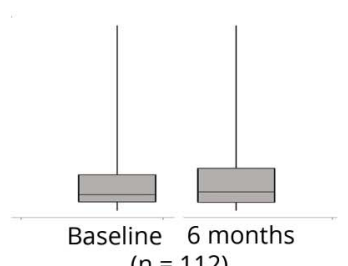

$(n=112)$

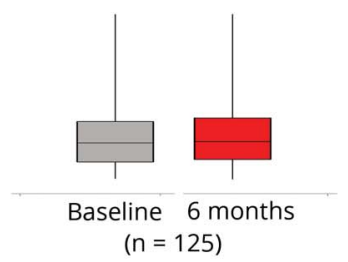

$(n=125)$

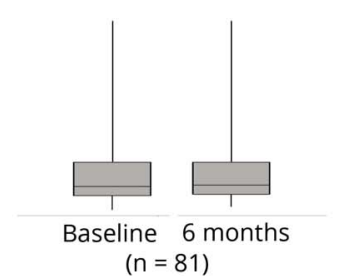

$(n=81)$

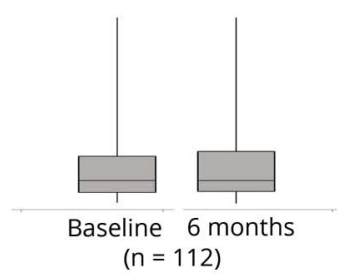

$(n=112)$

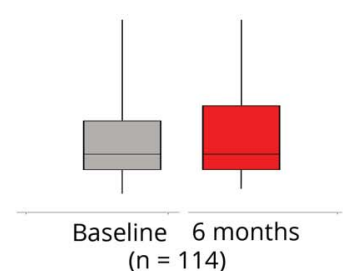

$(n=114)$

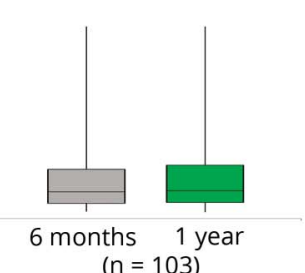

$(n=103)$
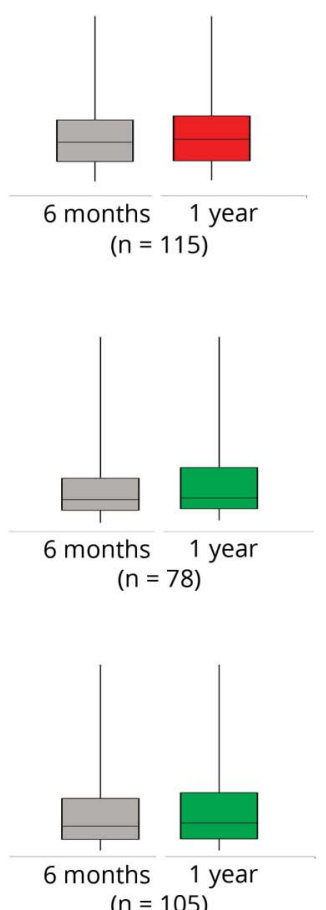

Boxplots showing range, interquartile range (IQR), and median values of time taken to perform timed tests. Paired comparisons of calculated velocity (1/time in seconds) were used to determine significant vs insignificant change in order to include those unable to complete the test. These are displayed as time taken to complete each task (rather than velocity) to aid visual interpretation. Comparisons of baseline and year 1, baseline and 6 months, and 6 months and 1 year are shown. The numbers differ depending on the number of patients completing each test at both visits. Blue shows significant change $(p<0.05)$ over 1 year; red shows if change is seen over both 6-month periods; and green shows change in only the green 6-month window. Some patients were very slow, and those taking $>25$ seconds to complete a test are not displayed but are included in median and IQR calculations.

\section{Estimated sample size for trials}

Estimated clinical trial sample size is highly dependent on the expected treatment effect; the smaller the effect size, the larger the sample required (table 4). For example, with the inclusion of ambulant patients of all disease severities, a total of 328 patients (164 in both the treatment and placebo groups) would be needed to detect a $50 \%$ reduction in disease progression (i.e., half the deterioration seen in the current sample) over 1 year compared to 90 patients (45 in each group) needed to detect halting in progression. The a-NSAA was chosen for its capability to detect change as demonstrated by the highest overall SRM in the current analysis. Limiting a clinical trial to a subset of patients in the moderate severity group at baseline, who showed the greatest changes in a-NSAA scores over 1 year, would reduce the total sample size to 176 for a $50 \%$ reduction in progression and 46 to detect a halt in progression. A treatment that is anticipated to improve muscle function, producing a greater effect size than simply halting progression, would require even fewer patients.

The 6MWT would require 216 ambulant patients to detect a halting of progression. However, as reflected by the high SRM in the severe-ambulant population, if trials were limited to the severe-ambulant subgroup of patients, 42 patients would be needed to detect a halting in progression with the 6MWT. 
Table 3 Scores in LGMD2B and Miyoshi myopathy

\begin{tabular}{|c|c|c|c|c|c|c|c|c|c|}
\hline \multirow[b]{2}{*}{ Outcome } & \multicolumn{4}{|c|}{ LGMD2B } & \multicolumn{4}{|c|}{ Miyoshi myopathy } & \multirow{2}{*}{$\begin{array}{l}\text { Kruskal- } \\
\text { Wallis } \\
\text { test of } \\
\text { difference } \\
\text { between } \\
\text { groups } \\
p \text { Value }\end{array}$} \\
\hline & $\mathbf{n}$ & $\begin{array}{l}\text { Median } \\
\text { (range) }\end{array}$ & $p$ Value & SRM & $\mathbf{n}$ & $\begin{array}{l}\text { Median } \\
\text { (range) }\end{array}$ & $\begin{array}{l}p \\
\text { Value }\end{array}$ & SRM & \\
\hline Total North Star score & 67 & $-2.00(-14.0$ to 5.00$)$ & $<0.0001$ & 0.69 & 35 & $-2.00(-16.0$ to 7.00$)$ & 0.0015 & 0.50 & 0.8663 \\
\hline Total MFM Score & 84 & $-1.00(-13.0$ to 6.00$)$ & $<0.0001$ & 0.46 & 48 & $-1.00(-10.0$ to 6.00$)$ & 0.0131 & 0.38 & 0.87 \\
\hline MFM D1 score & 85 & $-1.00(-6.00$ to 6.00$)$ & 0.0006 & 0.36 & 49 & $0.00(-8.00$ to 3.00$)$ & 0.0042 & 0.42 & 0.8898 \\
\hline MFM D2 score & 91 & 0.00 (-8.00 to 4.00$)$ & 0.0201 & 0.25 & 49 & $0.00(-4.00$ to 5.00$)$ & 0.4588 & 0.08 & 0.8873 \\
\hline MFM D3 score & 92 & $0.00(-3.00$ to 2.00$)$ & 0.0026 & 0.32 & 51 & $0.00(-6.00$ to 2.00$)$ & 0.2350 & 0.19 & 0.6595 \\
\hline MMT shoulder abduction & 97 & $0.00(-4.00$ to 3.00$)$ & 0.0530 & 0.21 & 51 & 0.00 (-2.00 to 2.00$)$ & 0.2754 & 0.18 & 0.9883 \\
\hline MMT shoulder flexion & 97 & $0.00(-3.00$ to 2.00$)$ & 0.2873 & 0.12 & 51 & $0.00(-2.00$ to 3.00$)$ & 0.8111 & 0.02 & 0.8958 \\
\hline MMT elbow flexion biceps & 97 & $0.00(-4.00$ to 4.00$)$ & 0.1284 & 0.16 & 51 & $0.00(-3.00$ to 3.00$)$ & 0.0505 & 0.25 & 0.9713 \\
\hline $\begin{array}{l}\text { MMT elbow flexion } \\
\text { brachioradialis }\end{array}$ & 97 & $0.00(-5.00$ to 3.00$)$ & 0.3926 & 0.11 & 51 & $0.00(-3.00$ to 3.00$)$ & 0.7598 & 0.03 & 0.9249 \\
\hline MMT wrist extension & 97 & $0.00(-3.00$ to 3.00$)$ & 0.9115 & 0.01 & 51 & $0.00(-2.00$ to 2.00$)$ & 0.6209 & 0.09 & 0.8412 \\
\hline MMT wrist flexion & 97 & $0.00(-4.00$ to 3.00$)$ & 0.0750 & 0.19 & 51 & $0.00(-4.00$ to 3.00$)$ & 0.0444 & 0.28 & 0.9326 \\
\hline MMT knee extension & 96 & $0.00(-3.00$ to 4.00$)$ & 0.9472 & 0.04 & 51 & $0.00(-3.00$ to 5.00$)$ & 0.5997 & 0.06 & 0.9994 \\
\hline MMT ankle dorsiflexion & 96 & $0.00(-5.00$ to 4.00$)$ & 0.0536 & 0.20 & 51 & $0.00(-3.00$ to 6.00$)$ & 0.1403 & 0.14 & 0.9966 \\
\hline MMT ankle inversion & 96 & $0.00(-4.00$ to 4.00$)$ & 0.8853 & 0.01 & 51 & $0.00(-4.00$ to 5.00$)$ & 0.7866 & 0.04 & 0.9927 \\
\hline MMT ankle eversion & 96 & $0.00(-5.00$ to 3.00$)$ & 0.0701 & 0.22 & 51 & $0.00(-6.00$ to 3.00$)$ & 0.1469 & 0.22 & 0.9941 \\
\hline $\begin{array}{l}\text { MMT ankle plantarflexion } \\
\text { (knee straight) }{ }^{\mathrm{a}}\end{array}$ & 78 & $0.00(-5.00$ to 8.00$)$ & 0.6160 & 0.02 & 44 & $0.00(-10.0$ to 7.00$)$ & 0.0062 & 0.36 & 0.0455 \\
\hline $\begin{array}{l}\text { MMT ankle plantarflexion } \\
\text { (knee flexed) }\end{array}$ & 86 & $0.00(-6.00$ to 5.00$)$ & 0.2716 & 0.11 & 50 & $0.00(-2.00$ to 5.00$)$ & 0.0876 & 0.17 & 0.6968 \\
\hline MMT hip extension & 88 & $0.00(-5.00$ to 4.00$)$ & 0.2450 & 0.12 & 50 & $0.00(-7.00$ to 2.00$)$ & 0.4626 & 0.37 & 0.423 \\
\hline MMT knee flexion & 89 & $0.00(-5.00$ to 3.00$)$ & 0.3173 & 0.14 & 50 & $0.00(-3.00$ to 2.00$)$ & 0.0147 & 0.20 & 0.3917 \\
\hline MMT hip Abduction & 89 & $0.00(-7.00$ to 7.00$)$ & 0.2638 & 0.12 & 50 & $0.00(-4.00$ to 6.00$)$ & 0.5599 & 0.10 & 0.4836 \\
\hline MMT hip Adduction & 89 & $0.00(-5.00$ to 3.00$)$ & 0.0025 & 0.32 & 50 & $0.00(-5.00$ to 5.00$)$ & 0.6168 & 0.06 & 0.2017 \\
\hline MMT hip flexion & 92 & $0.00(-5.00$ to 2.00$)$ & 0.1230 & 0.19 & 51 & $0.00(-3.00$ to 4.00$)$ & 0.1110 & 0.20 & 0.8431 \\
\hline MMT elbow extension & 92 & $0.00(-5.00$ to 4.00$)$ & 0.0653 & 0.20 & 51 & $0.00(-3.00$ to 4.00$)$ & 0.8632 & 0.02 & 0.6868 \\
\hline HHM elbow flexion biceps, Ib & 91 & $-0.30(-17.6$ to 11.00$)$ & 0.0904 & 0.24 & 48 & $-0.85(-23.6$ to 15.10$)$ & 0.0498 & 0.23 & 0.7967 \\
\hline $\begin{array}{l}\text { HHM elbow flexion } \\
\text { brachioradialis, Ib }\end{array}$ & 91 & $-0.60(-20.5$ to 8.20$)$ & 0.2003 & 0.19 & 48 & $0.20(-21.0$ to 15.20$)$ & 0.5768 & 0.09 & 0.9248 \\
\hline HHM wrist extension, Ib $^{a}$ & 93 & $-1.40(-17.4$ to 14.60$)$ & 0.0173 & 0.21 & 50 & $1.40(-15.5$ to 17.60$)$ & 0.0798 & 0.15 & 0.0187 \\
\hline HHM wrist flexion, Ib & 93 & $-0.10(-16.6$ to 15.30$)$ & 0.8544 & 0.03 & 48 & $0.60(-10.4$ to 7.60$)$ & 0.5540 & 0.05 & 0.8952 \\
\hline HHM grip, Ib & 93 & $-1.00(-186$ to 87.10$)$ & 0.0085 & 0.27 & 42 & $-2.00(-85.0$ to 62.90$)$ & 0.1015 & 0.25 & 0.9728 \\
\hline HHM pinch grip, Ib & 93 & $-1.00(-31.0$ to 40.00$)$ & 0.0175 & 0.19 & 42 & $0.00(-27.0$ to 16.00$)$ & 0.2026 & 0.28 & 0.9623 \\
\hline HHM knee extension, lb & 81 & $-0.10(-30.3$ to 15.50$)$ & 0.2259 & 0.17 & 42 & $-1.10(-36.6$ to 19.70$)$ & 0.0215 & 0.24 & 0.5599 \\
\hline HHM knee flexion, lb & 73 & $-1.00(-11.6$ to 16.60$)$ & 0.0276 & 0.14 & 39 & $-1.00(-13.5$ to 20.00$)$ & 0.0011 & 0.21 & 0.6533 \\
\hline HHM hip abduction, Ib & 86 & $-0.10(-14.7$ to 19.20$)$ & 0.8929 & 0.08 & 48 & $0.90(-36.5$ to 26.10$)$ & 0.0948 & 0.11 & 0.3955 \\
\hline
\end{tabular}




\begin{tabular}{|c|c|c|c|c|c|c|c|c|c|}
\hline \multirow[b]{2}{*}{ Outcome } & \multicolumn{4}{|c|}{ LGMD2B } & \multicolumn{4}{|c|}{ Miyoshi myopathy } & \multirow{2}{*}{$\begin{array}{l}\text { Kruskal- } \\
\text { Wallis } \\
\text { test of } \\
\text { difference } \\
\text { between } \\
\text { groups } \\
p \text { Value }\end{array}$} \\
\hline & $\mathbf{n}$ & $\begin{array}{l}\text { Median } \\
\text { (range) }\end{array}$ & $p$ Value & SRM & $\mathbf{n}$ & $\begin{array}{l}\text { Median } \\
\text { (range) }\end{array}$ & $\begin{array}{l}p \\
\text { Value }\end{array}$ & SRM & \\
\hline HHM hip adduction, Ib & 82 & $-1.00(-20.8$ to 13.40$)$ & 0.1396 & 0.16 & 41 & $-1.10(-15.5$ to 17.20$)$ & 0.2555 & 0.07 & 0.9905 \\
\hline HHM ankle dorsiflexion, Ib & 68 & $-0.65(-18.5$ to 17.00$)$ & 0.0833 & 0.15 & 35 & $0.00(-22.2$ to 25.90$)$ & 0.8751 & 0.01 & 0.5334 \\
\hline $\begin{array}{l}\text { HHM ankle plantar flexors (knee } \\
\text { flexed), Ib }\end{array}$ & 71 & $-1.00(-23.0$ to 20.90$)$ & 0.0331 & 0.24 & 37 & $-1.20(-10.7$ to 16.10$)$ & 0.1155 & 0.11 & 0.9482 \\
\hline $\begin{array}{l}\text { HHM ankle plantar flexors (knee } \\
\text { straight), lb }\end{array}$ & 71 & $-1.00(-27.0$ to 17.30$)$ & 0.1283 & 0.18 & 36 & $-0.45(-30.6$ to 14.40$)$ & 0.9234 & 0.08 & 0.69 \\
\hline Brooke Upper Extremity Scale & 97 & $0.00(-1.00$ to 2.00$)$ & 0.0301 & 0.21 & 51 & $0.00(-1.00$ to 1.00$)$ & 0.3877 & 0.17 & 0.9764 \\
\hline ACTIVLIM total score & 95 & $-1.00(-8.00$ to 4.00$)$ & $<0.0001$ & 0.51 & 51 & $-1.00(-8.00$ to 6.00$)$ & 0.0520 & 0.28 & 0.8076 \\
\hline Jebsen writing time taken, s & 95 & $-0.20(-14.4$ to 28.10$)$ & 0.6479 & 0.15 & 49 & $0.50(-10.5$ to 6.40$)$ & 0.5693 & 0.04 & 0.9795 \\
\hline $\begin{array}{l}\text { 6-min walk test total distance, } \\
\text { meters/min }\end{array}$ & 65 & $-8.00(-123$ to 71.00$)$ & 0.0137 & 0.33 & 34 & $-15.50(-108$ to 142.0$)$ & 0.0607 & 0.24 & 0.9881 \\
\hline
\end{tabular}

Abbreviations: HHM = hand-held myometry; LGMD2B = limb girdle muscular dystrophy type 2B; MFM = Motor Function Measure; MMT = manual muscle testing; SRM = standardized response mean.

This table shows the change scores over 1 year for patients with a diagnosis of LGMD2B or Miyoshi myopathy. Change scores were compared between groups with the Kruskal-Wallis test and Steel-Dwass-Critchlow-Fligner control for multiple comparisons. The SRM is a measure of effect size demonstrated by each test, shown for each diagnostic group. Overall functional scores of the MFM and adapted North Star Ambulatory Assessment did not differ between diagnostic subgroups.

a Only 2 muscle groups (ankle plantar flexion and wrist extension) showed a difference between these 2 groups.

\section{Discussion}

This analysis supports the use of specified physical and patientreported outcome measures in the assessment of dysferlinopathy by demonstrating clinically detectable deterioration in muscle strength and function and self-reported deterioration over 6 months and 1 year in a large cohort of patients.

Defining a set of disease specific tests is useful in coordinating further research and patient follow-up and developing clinical trial outcome measures. The most sensitive assessments for monitoring progression in dysferlinopathy that were identified in this study are the a-NSAA, MFM-20, timed 10-meter walk, and Timed Up and Go; they demonstrated consistent change over both 6 months and 1 year with a relatively high SRM. Other tests such as the Brooke and some MMT assessments showed change over 1 year but not 6 months, suggesting that they are less sensitive scales. This was also true for D3 (distal function) of the MFM, consistent with other published crosssectional data on its poor suitability for this population. ${ }^{14}$ Some tests such as the 6MWT and MFM D2 domain changed over one 6-month window but not the other. This poor repeatability of demonstrable change makes these measures less reliable in assessing the dysferlinopathy patient cohort as a whole.

The 6MWT showed the highest SRM for the severely affected ambulant patients, perhaps capturing a large deterioration in the walking pace of some of these weak patients as they lose ambulation. However, this is unlikely to be used in clinical trials, particularly because this subgroup of patients is small (37 severe-ambulant patients in this study), thus reducing the number of patients available to appropriately power a study.

Trials in rare diseases are often forced to rely on small cohort sizes. Here, we show that while variation in physical progression can be high in dysferlinopathy, sensitive outcome measures can be identified (a-NSAA, 10-meter walk, etc.), particularly in ambulant patients. We confirm that a moderate disease severity group based on the a-NSAA could be identified, making it possible to power a clinical trial with a reasonably sized sample. The actual number needed would depend on the expected treatment effect over 1 year. Numbers needed for a trial could be further reduced by using this longitudinal natural history sample as a control group for future clinical studies. ${ }^{19}$ In addition, longer evaluation times and identification of more sensitive scoring systems could further reduce the number of participants needed for effective clinical trials. Future work aiming to assess the cohort by modeling methods will look at progression based on a variety of disease and environmental factors to attempt to determine whether any subgroups exist with differing rates of progression. Any particularly fast-progressing group would be very good candidates for potential trials in terms of both patient benefit and reduced sample size requirement.

Increasing the sensitivity and utility of functional scoring systems across the disease spectrum requires the creation of 
Table 4 Sample size estimates for a placebo-controlled clinical trial

\begin{tabular}{|c|c|c|c|c|c|}
\hline \multirow[b]{2}{*}{ Target study population } & \multicolumn{5}{|c|}{ Target treatment effect, $\mathrm{n}$} \\
\hline & $\begin{array}{l}50 \% \text { Reduction in } \\
\text { progression }\end{array}$ & $\begin{array}{l}75 \% \text { Reduction in } \\
\text { progression }\end{array}$ & $\begin{array}{l}\text { Halting of } \\
\text { progression }\end{array}$ & $\begin{array}{l}20 \% \\
\text { Improvement }\end{array}$ & $\begin{array}{l}\mathbf{5 0 \%} \\
\text { Improvement }\end{array}$ \\
\hline All ambulant patients & 328 & 148 & 90 & 62 & 42 \\
\hline $\begin{array}{l}\text { Moderate patients only (baseline } \\
\text { a-NSAA score 11-40) }\end{array}$ & 176 & 80 & 46 & 34 & 22 \\
\hline
\end{tabular}

Abbreviation: a-NSAA = adapted North Star Ambulatory Assessment.

Sample size estimates for a placebo-controlled clinical trial are based on projected mean change in a-NSAA score for variable treatment effects over 1 year. The numbers represent the total sample size based on equally sized treatment and control groups. Calculations are based on an observed decrease in NSAA score in untreated patients of 2.4 overall and 3.8 among moderate patients, the expected control effect. Estimated change in a-NSAA score among treatment groups over 1 year is therefore as follows: $50 \%$ reduction, decrease of 1.2 (all) and 1.9 (moderate) in a-NSAA score; $75 \%$ reduction, decrease of 0.6 (all) and 0.9 (moderate) in a-NSAA score; halting of progression, no change in a-NSAA score; $20 \%$ improvement, increase of 0.5 (all) and 0.7 (moderate) in a-NSAA score; and $50 \%$ improvement, increase of 1.2 (all) and 1.9 (moderate) in a-NSAA score.

a disease-specific scale. We are working to streamline the a-NSAA and MFM-20 to remove redundant and less sensitive items and to combine elements of each scale using a Rasch analysis $^{20}$ to create a linearizable, dysferlin-specific score. This modified scale, called the North Star Assessment for Dysferlinopathy, will be validated with the 2- and 3-year COS visits and will be assessed with Rasch analysis to determine whether the new scale is capable of measuring change over a wider proportion of the patient population over time.

Characterizing which individual muscles demonstrate most rapid deterioration in dysferlinopathy is useful for both monitoring progression and targeting potential therapeutics, some of which involve local intramuscular injections. ${ }^{21}$ These results over 1 year show some sensitivity to change of a few distal muscle groups in nonambulant patients, in whom functional scores are less useful. However, in ambulant

Table 5 Intraclass correlation coefficient between screening and baseline assessments for functional tests carried out at a maximum of 90 days apart

\begin{tabular}{llll}
\hline Test & Intraclass correlation & $\mathbf{n}$ & Multiple \\
\hline NSAA & 0.99 & 132 & 119 \\
\hline MFM total score & 0.99 & 170 & 150 \\
\hline Time to stand & 0.85 & 91 & 77 \\
\hline Time to walk/run 10 $\mathbf{m}$ & 0.99 & 127 & 114 \\
\hline Timed Up and Go & 0.84 & 112 & 104 \\
\hline Time to climb 4 steps & 0.93 & 109 & 101 \\
\hline Time to descend 4 steps & 0.53 & 108 & 101 \\
\hline 6-min walk distance & 0.97 & 129 & 121 \\
\hline ACTIVLIM & 0.97 & 174 & 167 \\
\hline
\end{tabular}

Abbreviations: MFM = Motor Function Measure; NSAA = North Star Ambulatory Assessment.

A high intraclass correlation demonstrates consistency between screening and baseline assessments. patients, there is a low responsiveness and high variability of MMT and HHD results because measures of specific muscle change. Other measures of strength, longer time scales, and MRI may be needed to monitor effects of local treatments.

In all tests, a small number of individuals of all ages and disease severities improved their time or qualitative functional score over 1 year. While in some this may reflect a true improvement in function, we would not expect an improvement in underlying pathology. Therefore, it is likely that some of this improvement can be attributed to potentially confounding factors. With functional scales, improvement may be due to a learning effect ${ }^{22}$; that is, patients become more practiced at certain tests, although we attempted to mitigate this by having all patients perform a full assessment at screening. Some intertester variation in scoring is also possible because, although all were trained by the same provider, different physiotherapists conducted consecutive patient visits at some sites. However, we anticipate this effect to be small because the functional assessments used have previously demonstrated high intertester reliability in other diseases, ${ }^{23-25}$ and intraclass correlation comparison of baseline and screening results (table 5) shows consistency of scoring, particularly for the a-NSAA (intraclass correlation 0.99), on which much of this analysis is based. Finally, this may simply reflect environmental, physiologic, or individual factors such as motivation or fatigue, which can cause natural fluctuations in performance on functional tests ${ }^{22}$ on the background of more slowly progressing pathology. If trends in scores are maintained in future visits, suggesting a true subgroup of static or even functionally improving patients, this will be revisited to assess for potential disease modifiers.

The ACTIVLIM is a rating scale with documented high sensitivity in many neuromuscular conditions. ${ }^{16,26}$ We have shown that this holds true for the dysferlinopathy population, who show changes in score across all levels of function. A very small number of patients reported an improvement in the ability to perform tasks of daily living. These patients had undertaken lifestyle changes, including weight loss, dietary change, and participation in physiotherapy. Future work will explore and capture patient access to physiotherapy, 
participation in exercise, and the use of aids and adaptations in the home and workplace. These findings suggest that the ACTIVLIM is a reliable patient-reported outcome measure in dysferlinopathy that is a valuable complementary tool for clinical trials at any stage of the disease.

There are several limitations of this study. The first is the relatively short period of time over which change was examined; this will be addressed in future analysis of this 3 -year study. Second, the use of ordinal, rather than continuous, functional scales presented challenges in data analysis, necessitating the use of medians, making intuitive interpretation more difficult. However, these scales also have benefits because a single point change on a functional change necessarily represents a clinically, rather than simply statistically, noticeable change. Future work will explore the potential to linearize these Rasch-based measures, allowing us to keep the benefits of these scales while providing the opportunity to subject them to more rigorous parametric statistics.

Although function is measured, the importance attributed by patients to the loss of ability to perform 1 particular action over another is not measured here. To clarify the clinical significance of the statistically significant changes demonstrated here, further correlations are needed between these functional and patient-reported measures, as well as consideration of patient valuation of the importance of the loss of individual functions.

Our current assessment of arm function is limited in the scales currently used in this study. Further work is required to develop or determine suitable measures for upper limb function.

This study demonstrates significant population-level change over 6 months and 1 year in several functional and patientreported measures. We anticipate that the planned combination of the most sensitive elements of the a-NSAA and MFM to create a dysferlin-specific score will produce an important measure that will become the basis for assessment of progression in dysferlinopathy regardless of ambulatory status. This measure combined with MRI data and further patient subgroup analysis will add to the pathophysiologic understanding and trial readiness of the dysferlinopathy population and may further reduce the cohort size required to power potential clinical trials.

\section{Author contributions}

Ursula Moore: analysis or interpretation of the data, statistical analysis, drafting or revising the manuscript for intellectual content. Marni Jacobs: statistical analysis. Meredith James, analysis or interpretation of the data, drafting or revising the manuscript for intellectual content. Anna Mayhew and Roberto Fernandez Torron: analysis or interpretation of the data, drafting or revising the manuscript for intellectual content. Jia Feng: analysis or interpretation of the data, statistical analysis.
Avital Cnaan: design or conceptualization of the study, drafting or revising the manuscript for intellectual content. Karen Bettinson: major role in the acquisition of data, drafting or revising the manuscript for intellectual content. Laura Rufibach: design or conceptualization of the study, drafting or revising the manuscript for intellectual content. Robert Muni Lofra, Andrew M. Blamire, and Pierre G. Carlier: design or conceptualization of the study, major role in the acquisition of data, drafting or revising the manuscript for intellectual content. Plavi Mittal: design or conceptualization of the study, drafting or revising the manuscript for intellectual content. Michelle Eagle: design or conceptualization of the study, major role in the acquisition of data, drafting or revising the manuscript for intellectual content. Linda Lowes, Lindsay Alfano, Kristy Rose, Tina Duong, Katherine Berry, Elena Montiel-Morillo, Irene Pedrosa-Hernández, Scott E. Holsten, Mohammed Sanjak, Ai Ashida, Chikako Sakamoto, Tatyuki Tateishi, Hiroyuki Yajima, Aurélie Canal, Gwenn Olliver, Valerie Decostre, Bosco Mendez, Nieves Sánchez-Aguilera Práxedes, Simone Thiele, Catherine Siener, Jeannine Sheierbecker, Julaine Florence, Bruno Vandevelde, Brittney DeWolf, Meghan Harman, Richard Gee, Juliane Prugel, Elke Maron, and Heather Hilsden: major role in the acquisition of data, drafting or revising the manuscript for intellectual content. Hanns Lochmüller: design or conceptualization of the study, drafting or revising the manuscript for intellectual content. Ulrike Grieben, Simone Spuler, Carolina Tesi Rocha, John W. Day, Kristi J. Jones, Diana X. Bharucha-Goebel, Emmanuelle Salort-Campana, Matthew Harms, Alan Pestronk, Sabine Krause, Olivia Schreiber-Katz, Maggie C. Walter, Carmen Paradas, Jean-Yves Hogrel, Tanya Stojkovic, Shin'ich Takeda, Madoka Mori-Yoshimura, Elena Bravver, Susan Sparks, Jordi Díaz-Manera, Luca Bello, Claudio Semplicini, Elena Pegoraro, Jerry R. Mendell, and Kate Bushby: design or conceptualization of the study, major role in the acquisition of data, drafting or revising the manuscript for intellectual content. Volker Straub: design or conceptualization of the study, major role in the acquisition of data, drafting or revising the manuscript for intellectual content, overall responsibility for the content of this paper. For Study Group: the Jain Consortium: All members of the Jain Consortium are listed in the Appendix. All members of the study group played a role in acquisition of data.

\section{Acknowledgment}

This study has been possible only thanks to the international collaboration of several specialized centers promoted by the Jain Foundation. The Jain COS Consortium thanks the study participants and their families for their invaluable contributions and acknowledges the ongoing support that the Jain Foundation provides in the development, management, and analysis of this study. The Jain Foundation, based in Seattle, WA, is focused entirely on LGMD2B/dysferlinopathy/ Miyoshi myopathy. The foundation does not solicit funding from patients but instead funds research and clinical studies worldwide with the goal of finding treatments for dysferlinopathy. Please visit jain-foundation.org for more information 
about the foundation. If you are a patient with dysferlinopathy, please consider enrolling in their interactive dysferlinopathy registry, which seeks to build a strong, engaged, and supportive community (patients@jain-foundation.org).

\section{Study funding}

The estimated US $\$ 4$ million needed to fund this study is being provided by the Jain Foundation. The John Walton Centre Muscular Dystrophy Research Centre is part of the
MRC Centre for Neuromuscular Diseases (grant MR/ K000608/1).

\section{Disclosure}

The authors report no disclosures relevant to the manuscript. Go to Neurology.org/N for full disclosures.

\section{Publication history}

Received by Neurology May 4, 2018. Accepted in final form October 1, 2018.

\section{Appendix 1 Coinvestigators: The Jain COS Consortium}

\begin{tabular}{|c|c|}
\hline Coinvestigator & Affiliation and role in study \\
\hline Adrienne Arrieta, MS & Children's National Medical Center, Washington, DC; data management and training \\
\hline Esther Hwang & Jain Foundation, Seattle, WA; recruitment, development of assessment form \\
\hline Elaine Lee, PhD & Jain Foundation, Seattle, WA; recruitment, development of assessment forms \\
\hline Isabel IIIa, MD & Hospital de la Santa Creu i Sant Pau/CIBERER, Barcelona, Spain; site investigator \\
\hline Eduard Gallardo, MD & Hospital de la Santa Creu i Sant Pau/CIBERER, Barcelona, Spain; site investigator \\
\hline Izaskun Belmonte Jimeno, PT & Servei de Medicina F ísica i Rehabilitació, Hospital de la Santa Creu i Sant Pau, Barcelona, Spain; site investigator \\
\hline Jaume Llauger Rossello & Radiology Department, Universitat Autònoma de Barcelona, Hospital de la Santa Creu i Sant Pau, Barcelona, Spain; radiologist \\
\hline Bruce Harwick & $\begin{array}{l}\text { Department of Radiology, CMC Mercy Charlotte, Carolinas Healthcare System Neurosciences Institute, Charlotte, NC; NMR } \\
\text { technologist }\end{array}$ \\
\hline Jackie Sykes, RN, BSN & Carolinas HealthCare System, Charlotte, NC; study coordinator \\
\hline Brent Yetter, MS & Nationwide Children's Hospital, Columbus, $\mathrm{OH}$; study coordinator \\
\hline $\begin{array}{l}\text { Mark Smith, MS, DABMP, } \\
\text { RT (MR) }\end{array}$ & Department of Radiology, Nationwide Children's Hospital, Columbus, $\mathrm{OH}$; site investigator \\
\hline Bernard Lapeyssonie, PT & Neuromuscular and ALS Center, La Timone Hospital, Aix-Marseille Université, Marseille, France; site investigator \\
\hline David Bendahan, PhD & $\begin{array}{l}\text { Centre de Résonance, MagnétiqueBiologique et Médicale, UMR CNRS 7339, Marseille, France; Aix-Marseille Université, } \\
\text { Marseille, France; site investigator }\end{array}$ \\
\hline Yann Le Fur, PhD & Aix-Marseille Université, Marseille, France; site investigator \\
\hline Attarian Shahram, MD, PhD & Neuromuscular and ALS Center, La Timone Hospital, Aix-Marseille Université, Marseille, France; site investigator \\
\hline Testot-Ferry Albane, CRA & Neuromuscular and ALS Center, La Timone Hospital, Aix-Marseille Université, Marseille, France; study coordinator \\
\hline Eva M. Coppenrath, MD & Department of Clinical Radiology, Ludwig-Maximilians-University Munich, Germany; site investigator \\
\hline Elizabeth Harris, MD & John Walton Muscular Dystrophy Research Centre, Newcastle Upon Tyne, UK; clinical investigator \\
\hline Michela Guglieri, MD & John Walton Muscular Dystrophy Research Centre, Newcastle Upon Tyne, UK; clinical investigator \\
\hline Teresinha Evangelista, MD & The John Walton Muscular Dystrophy Research Centre, Newcastle Upon Tyne, UK; clinical investigator \\
\hline Alex Murphy, MD & The John Walton Muscular Dystrophy Research Centre, Newcastle Upon Tyne, UK; clinical investigator \\
\hline Dionne Moat & The John Walton Muscular Dystrophy Research Centre, Newcastle Upon Tyne, UK; clinical investigator \\
\hline Tim Hodgson, MClinRES & Magnetic Resonance Centre, Institute for Cellular Medicine, Newcastle University, Newcastle Upon Tyne, UK; site investigator \\
\hline Dorothy Wallace, BSc & Magnetic Resonance Centre, Institute for Cellular Medicine, Newcastle University, Newcastle Upon Tyne, UK; site investigator \\
\hline Louise Ward, DCR & Magnetic Resonance Centre, Institute for Cellular Medicine, Newcastle University, Newcastle Upon Tyne, UK; site investigator \\
\hline Debra Galley & Magnetic Resonance Centre, Newcastle University, Newcastle Upon Tyne, UK; radiology assistant \\
\hline Chiara Calore & University of Padova, Padova, Italy, site investigator \\
\hline
\end{tabular}


Appendix 1 (continued)

\begin{tabular}{|c|c|}
\hline Coinvestigator & Affiliation and role in study \\
\hline Alessandro Rampado, MRT & Radiology Unit, Department of Medicine, University of Padova, Padova, Italy; site investigator \\
\hline Teresa Gidaro & Institut de Myologie, Paris, France; site investigator \\
\hline Suna Turk, MSc & AIM \& CEA NMR Laboratory, Institute of Myology, Pitié-Salpêtrière University Hospital, 47-83, Paris, France; site investigator \\
\hline Laurent Servais & Institut de Myologie, Paris, France; site investigator \\
\hline Cyrille Theis & Institut de Myologie, Paris, France; site investigator \\
\hline Oumar Diabaté & Institut de Myologie, Paris, France; study coordinator \\
\hline Linda Schimmoeller & Washington University, St. Louis, MO; study coordinator \\
\hline Glenn Foster, RTR (MR) & Center for Clinical Imaging Research CCIR, Washington University, St. Louis, MO; site investigator \\
\hline Pilar Carbonell, MD & Hospital U. Virgen del Rocío/Instituto de Biomedicina de Sevilla, Seville, Spain; site investigator \\
\hline Macarena Cabrera, MD & Hospital U. Virgen del Rocío/Instituto de Biomedicina de Sevilla, Seville, Spain; site investigator \\
\hline Yolanda Morgado, MD & Hospital U. Virgen de Valme/Instituto de Biomedicina de Sevilla, Seville, Spain; site investigator \\
\hline Susana Rico Gala, MD & Department of Radiology, Hospital U. Virgen de Valme, Seville, Spain; site investigator \\
\hline Jennifer Perez & Stanford University School of Medicine, Stanford, CA; study coordinator \\
\hline Anne Marie Sawyer, FSMRT & Lucas Centre for Imaging, Stanford University School of Medicine, Stanford, CA; site investigator \\
\hline Nigel F. Clarke, MD & Institute for Neuroscience and Muscle Research, Sydney, Australia; site investigator \\
\hline Sarah Sandaradura, MD & Institute for Neuroscience and Muscle Research, Sydney, Australia; site investigator \\
\hline Roula Ghaoui, MD & Institute for Neuroscience and Muscle Research, Sydney, Australia; site investigator \\
\hline Kayla Cornett, Ex Phys & Institute for Neuroscience and Muscle Research, Sydney, Australia; site investigator \\
\hline Claire Miller, PT & Institute for Neuroscience and Muscle Research, Sydney, Australia; site investigator \\
\hline Sheryl Foster, MHIthSc & Department of Radiology, Westmead Hospital; Faculty of Health Sciences, University of Sydney, Australia; site investigator \\
\hline Anthony Peduto, MBBS & Department of Radiology, Westmead Hospital; Faculty of Health Sciences, University of Sydney, Australia; site investigator \\
\hline Noriko Sato, MD, PhD & Department of Radiology, National Center Hospital, National Center of Neurology and Psychiatry, Tokyo, Japan; site investigator \\
\hline Takeshi Tamaru, MRT & Department of Radiology, National Center Hospital, National Center of Neurology and Psychiatry, Tokyo, Japan; site investigator \\
\hline Yoko Kobayashi, MD & National Center of Neurology and Psychiatry, Tokyo, Japan; site investigator \\
\hline Ai Ashida, PT & National Center of Neurology and Psychiatry, Tokyo, Japan; site investigator \\
\hline Takahiro Nakayama, MD, PhD & Yokohama Rosai Hospital, Yokohama, Japan; study advisor \\
\hline $\begin{array}{l}\text { Kazuhiko Segawa, MD, } \\
\text { PhD }\end{array}$ & National Center of Neurology and Psychiatry, Tokyo, Japan; site investigator \\
\hline Sachiko Ohtaguro & National Center of Neurology and Psychiatry, Tokyo, Japan; study assistant \\
\hline Harumasa Nakamura, MD & National Center of Neurology and Psychiatry, Tokyo, Japan; study advisor \\
\hline Maki Ohhata & National Center of Neurology and Psychiatry, Tokyo, Japan; study coordinator \\
\hline En Kimura, MD, PhD & National Center of Neurology and Psychiatry, Tokyo, Japan; study advisor \\
\hline Makiko Endo & National Center of Neurology and Psychiatry, Tokyo, Japan; study coordinator \\
\hline Nora Brody, PT, DPT & Children's National Health System, Washington, DC: site investigator \\
\hline $\begin{array}{l}\text { Meganne E. Leach, MSN, } \\
\text { APRN }\end{array}$ & Children's National Health System, Washington, DC: site investigator \\
\hline Allyn Toles & Children's National Health System, Washington, DC: study coordinator \\
\hline Stanley T. Fricke, PhD & Department of Diagnostic Imaging and Radiology, Children's National Health System, Washington, DC; site investigator \\
\hline Hansel J. Otero, MD & Department of Diagnostic Imaging and Radiology, Children's National Health System, Washington DC; site investigator \\
\hline
\end{tabular}




\section{References}

1. Bushby K, Straub V. One gene, one or many diseases? Simplifying dysferlinopathy. Neurology 2010;75:298-299.

2. Nguyen K, Bassez G, Bernard R, et al. Dysferlin mutations in LGMD2B, Miyoshi myopathy, and atypical dysferlinopathies. Hum Mutat 2005;26:165.

3. Krahn M, Beroud C, Labelle V, et al. Analysis of the DYSF mutational spectrum in a large cohort of patients. Hum Mutat 2009;30:E345-E375.

4. Harris E, Bladen CL, Mayhew A, et al. The Clinical Outcome Study for Dysferlinopathy: an international multicenter study. Neurol Genet 2016;2:e89.

5. Bushby K, Finkel R, Wong B, et al. Ataluren treatment of patients with nonsense mutation dystrophinopathy. Muscle Nerve 2014;50:477-487.

6. Ryan NJ. Ataluren: first global approval. Drugs 2014;74:1709-1714.

7. Finkel RS, Mercuri E, Darras BT, et al. Nusinersen versus sham control in infantileonset spinal muscular atrophy. N Engl J Med 2017;377(18):1723-32.

8. Mah JK. Current and emerging treatment strategies for Duchenne muscular dystrophy. Neuropsychiatr Dis Treat 2016;12:1795-1807.

9. Shieh PB. Duchenne muscular dystrophy: clinical trials and emerging tribulations. Curr Opin Neurol 2015;28:542-546.

10. Fanin M, Angelini C. Progress and challenges in diagnosis of dysferlinopathy. Muscle Nerve 2016;54:821-835

11. Klinge L, Aboumousa A, Eagle M, et al. New aspects on patients affected by dysferlin deficient muscular dystrophy. J Neurol Neurosurg Psychiatry 2010;81:946-953.

12. Klinge L, Dean AF, Kress W, et al. Late onset in dysferlinopathy widens the clinical spectrum. Neuromuscul Disord 2008;18:288-290.

13. Angelini C, Peterle E, Gaiani A, Bortolussi L, Borsato C. Dysferlinopathy course and sportive activity: clues for possible treatment. Acta Myol 2011;30:127-132.

14. Woudt L, Di Capua GA, Krahn M, et al. Toward an objective measure of functional disability in dysferlinopathy. Muscle Nerve 2016;53:49-57.

15. Tasca G, Iannaccone E, Monforte M, et al. Muscle MRI in Becker muscular dystrophy. Neuromuscul Disord 2012;22(suppl 2):S100-S106.
16. Batcho CS, Van den Bergh PY, Van Damme P, Roy AJ, Thonnard JL, Penta M. How robust is ACTIVLIM for the follow-up of activity limitations in patients with neuromuscular diseases? Neuromuscul Disord 2016;26:211-220.

17. Husted JA, Cook RJ, Farewell VT, Gladman DD. Methods for assessing responsiveness: a critical review and recommendations. J Clin Epidemiol 2000;53:459-468.

18. Douglas CE, Michael FA. On distribution-free multiple comparisons in the one-way analysis of variance. Commun Stat 1991;20:127-139.

19. Mendell JR, Goemans N, Lowes LP, et al. Longitudinal effect of eteplirsen versus historical control on ambulation in Duchenne muscular dystrophy. Ann Neurol 2016;79:257-271.

20. Mayhew A, Cano S, Scott E, Eagle M, Bushby K, Muntoni F. Moving towards meaningful measurement: Rasch analysis of the North Star Ambulatory Assessment in Duchenne muscular dystrophy. Dev Med Child Neurol 2011;53: $535-542$.

21. ClinicalTrials.gov. rAAVrh74.MHCK7.DYSF.DV for Treatment of Dysferlinopathies [online]. Available at: clinicaltrials.gov/ct2/show/NCT02710500. Accessed August 24, 2018.

22. Wadsworth CT, Krishnan R, Sear M, Harrold J, Nielsen DH. Intrarater reliability of manual muscle testing and hand-held dynametric muscle testing. Phys Ther 1987;67: $1342-1347$.

23. Scott E, Eagle M, Mayhew A, et al. Development of a functional assessment scale for ambulatory boys with Duchenne muscular dystrophy. Physiother Res Int 2012;17:101-109.

24. Berard C, Payan C, Hodgkinson I, Fermanian J. A motor function measure for neuromuscular diseases: construction and validation study. Neuromuscul Disord $2005 ; 15: 463-470$.

25. Cuthbert SC, Goodheart GJ Jr. On the reliability and validity of manual muscle testing: a literature review. Chiropr Osteopat 2007;15:4.

26. Vandervelde L, Van den Bergh PY, Goemans N, Thonnard JL. ACTIVLIM: a Raschbuilt measure of activity limitations in children and adults with neuromuscular disorders. Neuromuscul Disord 2007;17:459-469. 


\section{Neurology}

\section{Assessment of disease progression in dysferlinopathy: A 1-year cohort study \\ Ursula Moore, Marni Jacobs, Meredith K. James, et al.}

Neurology 2019;92;e461-e474 Published Online before print January 9, 2019

DOI 10.1212/WNL.0000000000006858

This information is current as of January 9, 2019

Updated Information \& Services

References

Subspecialty Collections

Permissions \& Licensing

Reprints including high resolution figures, can be found at: http://n.neurology.org/content/92/5/e461.full

This article cites 25 articles, 4 of which you can access for free at: http://n.neurology.org/content/92/5/e461.full\#ref-list-1

This article, along with others on similar topics, appears in the following collection(s):

\section{All Neuromuscular Disease}

http://n.neurology.org/cgi/collection/all_neuromuscular_disease Outcome research

http://n.neurology.org/cgi/collection/outcome_research

Information about reproducing this article in parts (figures,tables) or in its entirety can be found online at:

http://www.neurology.org/about/about_the_journal\#permissions

Information about ordering reprints can be found online:

http://n.neurology.org/subscribers/advertise

Neurology ${ }^{\circledR}$ is the official journal of the American Academy of Neurology. Published continuously since 1951, it is now a weekly with 48 issues per year. Copyright Copyright ( 2019 The Author(s). Published by Wolters Kluwer Health, Inc. on behalf of the American Academy of Neurology.. All rights reserved. Print ISSN: 0028-3878. Online ISSN: 1526-632X.

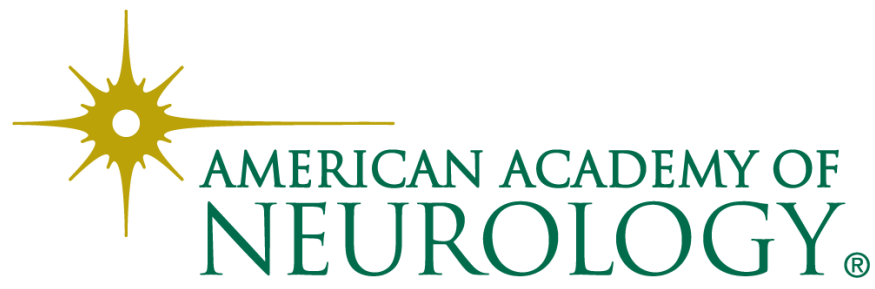

